Do Espírito do Lugar - Música, Estética, Silêncio, Espaço, Luz

I e II Residências Cistercienses de São Bento de Cástris (2013, 2014)

\title{
Ambiência monástica e prática litúrgico-musical pós-tridentinas no mosteiro de S. Bento de Cástris
}

\section{Antónia Fialho Conde}

Publisher: Publicações do Cidehus

Place of publication: Évora

Year of publication: 2016

Published on OpenEdition Books: 13

septembre 2016

Serie: Biblioteca - Estudos \& Colóquios

\section{G books}

http://books.openedition.org

\section{Electronic reference}

CONDE, Antónia Fialho. Ambiência monástica e prática litúrgico-musical pós-tridentinas no mosteiro de $S$. Bento de Cástris In: Do Espírito do Lugar - Música, Estética, Silêncio, Espaço, Luz: I e Il Residências Cistercienses de São Bento de Cástris (2013, 2014) [online]. Évora: Publicações do Cidehus, 2016 (generated 17 October 2016). Available on the Internet: <http://books.openedition.org/cidehus/1985> ISBN: 9782821875029. DOI: 10.4000/books.cidehus.1985.

The text is a facsimile of the print edition. 
Ambiência monástica e prática litúrgico-musical pós-tridentinas no mosteiro de $\mathrm{S}$. Bento de Cástris*

\section{Antónia Fialho Conde}

Abstract

In the current historiographical production there is a manifest interest for the history of female religiosity. The mystic phenomenon, the everyday life and the temporal dimension of the communities, in terms of familiar and social connection to the outside of cloistered spaces, manifestations of creativity and culture, are increasingly treated issues.

This interest is also expressed about the Cistercian Order in Portugal. In the female branch, the monastery of St. Benedict of Cástris, officially Cistercian for more than 700 years, has been the target of an interdisciplinary approach that intents to appreciate the impact of the reflections of the Council of Trent in the musical praxis of the nuns.

This community, subject to Alcobaça and controlled through Visitors, registers in its documentation not only the presence of nuns that sang and played various instruments, arising mainly from Évora region, a city with a recognized musical tradition, but also registers various expenses related with the musical practice of the monastery.

Keywords: S. Bento de Cástris, Cistercian Order, modern period, musical heritage

\section{Resumo}

Regista-se, na actual produção historiográfica, um interesse manifesto pela história da religiosidade feminina. $\mathrm{O}$ fenómeno místico, o viver quotidiano e a dimensão temporal das comunidades, em termos de ligação familiar e social ao exterior dos espaços-clausura, as manifestações de criatividade e cultura, são questões cada vez mais tratadas. Esse interesse manifesta-se também para a Ordem de Cister em Portugal, sendo que, no ramo feminino, o mosteiro de S. Bento de Cástris, oficialmente cisterciense há mais de 700 anos, vem sendo alvo de uma abordagem multidisciplinar que procura apreciar os reflexos do Concílio de Trento na praxis musical das religiosas. Esta comunidade, sujeita a Alcobaça e por ela controlada através dos Visitadores, regista na sua documentação não só a presença de religiosas cantoras e tangedoras de vários instrumentos, oriundas maioritariamente da região de Évora, cidade com uma tradição musical reconhecida, como diversas despesas relacionadas com a prática musical do mosteiro. 
Palavras-chave: S. Bento de Cástris, Ordem de Cister, período moderno, património musical

\section{Trento e a praxis musical nos mosteiros cistercienses: S. Bento de Cástris}

Se o Concílio de Trento (1545-1563) significou um controlo mais estrito da vida conventual feminina, nomeadamente no que respeita à clausura estrita ${ }^{1}$, nele também se debateu a questão da inteligibilidade da palavra divina perante a presença da música ${ }^{2}$, juntando anteriores preocupações no que concerne às palavras cantadas em comum, e que poderiam ofuscar a mensagem do texto. Embora a missa continuasse a ser celebrada em latim, o Concílio autorizou a tradução de alguns salmos, aspecto este que, tal como a gestão do canto, sua pronunciação e salmodia foi delegado nos sínodos provinciais. É essencialmente por esta razão que assistimos a uma grande variedade na música sacra pós-tridentina em termos europeus, com autonomias locais e regionais que a distinguem, assumindo soluções de compromisso entre as questões da inteligibilidade da palavra e dos atrativos jogos de sonoridades, resultado das práticas já instaladas.

Foi no Verão de 1562 , na preparação para a $22^{\mathrm{a}}$ sessão do Concílio de Trento, que a questão da música foi abordada, no capítulo "Abusos da Missa", tentando banir elementos seculares e lascivos que poderiam obscurecer a audição das palavras sagradas. Os decretos finais da $22^{\mathrm{a}}$ sessão foram menos precisos, mais gerais e atenuados que os apontados na sessão preparatória dessa mesma sessão, e as referências publicadas na sessão $24^{\mathrm{a}}$ em novembro de 1563 foram ainda menos prescritivas. Como exemplo, temos que um dos decretos preliminares não apenas bania atuações de música nas igrejas dos conventos, mas também a polifonia das monjas no seu coro $^{3}$. Na última sessão do Concílio, a 13 de dezembro de 1563 , as referências à música que devia ser tocada e cantada pelas monjas não estão presentes.

\footnotetext{
* O presente estudo insere-se no âmbito do Projecto FCT EXPL/EPH-PAT/2253/2013, "Projecto ORFEUS - A Reforma tridentina e a música no silêncio claustral: o mosteiro de S. Bento de Cástris", financiado por fundos nacionais através da FCT/MEC e co-financiado pelo Fundo Europeu de Desenvolvimento Regional (FEDER) através do COMPETE - Programa Operacional Factores de Competitividade (POFC) e do QREN.

${ }^{1}$ Sob este aspecto, cf. CREYTENS, Raimondo. "La riforma dei monasteri femminili dopo i Decreti Tridentini." Il Concilio di Trento e la riforma tridentina 1, 1963, pp. 45-84.

${ }^{2}$ Cf. CORSWAREM, Émilie, «La musique sacrée au lendemain du Concile de Trente », dossier Religion, regards pluriels, Université de Liège, Jul-2009.Disponível em http://hdl.handle.net/2268/110606 ( acesso: janeiro 2015).

${ }^{3}$ MONSON, Craig A., "Renewal, Reform and Reaction in Catholic Music" in European Music 1520-1640, (Ed. James Haar), The Boydel Press, 2006, pp. 401-421. Cf. ainda IDEM, 1995, Disembodied Voices. Music and Culture in an Early Modern Italian Convent. Berkeley / Los Angeles: University of California Press; IDEM, 2002, «The Council of Trent revisited». In Journal of the American Musicological Society, University of California Press, vol. 55, $\mathrm{n}^{\circ}$ 1, pp.1-37, acessível em http://www.jstor.org/stable/10.1525/jams.2002.55.1.1; IDEM, «Putting nun musicians in their place». In Women's Voices across Musical Worlds, ed. Jane Bernstein, Boston: Northeastern University Press, 2004, pp.118-141.
} 
A prática musical nos conventos tornava-se, assim, um dos aspectos mais dinâmicos da música católica no período moderno, pois o Concílio renovou e reformou, mas com diretrizes mínimas para a música, dependendo o seu impacto da máquina burocrática de Roma (com a criação de corpos típicos de uma organização administrativa centralizada, como a Sagrada Congregação do Concílio de Trento, a Sagrada Congregação de Bispos e Regulares, a Congregação dos Ritos Sagrados) e das hierarquias diocesanas e sínodos provinciais, com poderes reforçados pro Trento, como o que se verificou na diocese de Milão, com S. Carlos Borromeu:

(...) Flexibility of interpretations is apparent in local responses to the Ceremoniale episcoporum, promulgated by the Congregation of Sacred Rites in July 1600, as a guide to the ritual use of music. By observing the letter of the law, musicians sometimes arrived at varied and cretaive solutions, working within, bul also around, the law, and not entirely in accord with Rome's intentions. In responding to the Ceremoniale's prohibition of the organ during Lenet, for example, composers of music for Holy Week sometimes supplantede the organ with harpsichords, lutes, and archlutes. (...)

Em termos genéricos, temos que Trento renovou e reformou, mas com directrizes mínimas para a música. O seu impacto dependeu não só da burocracia de Roma como das hierarquias diocesanas e sínodos provinciais. A reforma dos textos litúrgicos (Breviário, 1568; Missal, 1570) com especial importância para a música tiveram lugar quase imediatamente a Pio V. A reforma do canto com Gregório XIII, sucessor de Pio V, teve lugar em 1577, antes de haver um reportório para canto impresso em 1614/15 pela Editio Medicaea.

Os livros para a missa e para o Ofício Divino são parte fundamental da liturgia, baseandose os seus textos na Sagrada Escritura e no Breviarium Romanum aprovado pelo Concílio. No caso de Cister em Portugal, a Bula "Pastoralis officii" instituíra, em 1567, a Congregação Autónoma de Santa Maria de Alcobaça. Esta passou a dispor, além das Constituições já existentes, de mecanismos que determinavam o quotidiano dos mosteiros cistercienses portugueses. As diretivas emanadas dos Capítulos Gerais e Juntas da Congregação são decisivas para a vida das comunidades, e devem ser entendidas no contexto espiritual do período moderno, da cultura do barroco e do espírito da Contrarreforma, distinto do primacial da Ordem de Cister, mas que se refletiu tanto na arquitetura dos espaços como na liturgia ou na prática musical ${ }^{4}$.

${ }^{4}$ GARCÍA FLORES, Antonio, Para mayor culto del ofico divino y servicio de Dios. Las iglesias de los monasterios cistercienses de la Congregación de Castilla (siglos XV-XIX), 2014. Sobre a vida conventual feminina, são pertinentes os estudos de EVANGELISTI, Silvia, «Monastic Poverty and Material Culture in Early Modern Italian Convents». In The 
Quanto ao Ofício Divino, e seus reflexos na música, os cistercienses conheceram várias reformas a partir do modelo inicial, estabelecido por Estêvão Harding e baseado no rito ambrosiano. Da primeira reforma (1134-1147), também conhecida como reforma bernardina, surgiu um novo Antifonário, repensando vários repertórios existentes e baseado no De Cantu, em que S. Bernardo apelava à "gravitas cisterciense", assente no espírito de racionalidade, e que reconduzia à unidade tonal. Para o canto, a Ordem estabelecia uma "meã maneira" de cantar, nem muito vagarosa, nem com muita pressa, demonstrando antes gravidade e devoção. Também para Cister, como para as demais ordens religiosas, o Concílio de Trento significou o reavivar da tradição da música para a missa, dando porém claras restrições à composição. No século XVII, a Ordem de Cister conheceu nova reforma, ainda como consequência do Concílio de Trento.

Também em Portugal se manifestou, ao longo do tempo, a importância da música sacra cisterciense, revelando-se em Breviários e Invitatórios. O seu conteúdo possibilita uma análise das práticas religiosas e sacramentais mais reproduzidas, bem como da jerarquia das festas, fornecendo elementos para o entendimento da vida monástica cisterciense de Quinhentos e Seiscentos, confrontando-a tanto com o exigido nas Constituições da Ordem como nas leis capitulares e recomendações das Visitas aos mosteiros.

É sobre esta realidade que particularizaremos a nossa análise, a partir do mosteiro cisterciense feminino de S. Bento de Cástris, onde a presença de religiosas ligadas à música foi uma constante. São religiosas cantoras, músicas e tangedoras ${ }^{5}$, que normalmente entravam no mosteiro com dote inferior, e que surgem especialmente desde a década de 80 do século XVI, procedendo de geografias distintas, mas maioritariamente de Évora, e a cuja tradição musical acabavam por estar ligadas: lembremos o prestígio da Escola de Música da Sé de Évora, e de todos os músicos ligados à sua atividade. Muitas das religiosas tinham tido certamente alguma formação em música, ainda que incipiente,

Historical Journal, Cambridge University Press, 2004, vol.47, nº1, pp.1-20. http://www.jstor.org/stable/4091543, HARNESS, Kelley, Echoes of Women's Voices: Music, Art, and Female Patronage in Early Modern Florence. Chicago / London: University of Chicago Press, 2006; POMATA, Gianna, ZARRI, Gabriella (dir.), I monasteri femminili come centri di cultura fra Rinascimento e Barocco, Rome, Edizioni di Storia e Letteratura, 2005. Para o caso português, CONDE, Antónia Fialho, 2014, «Modelos em vida, paradigmas na morte: a construção da perfeita religiosa em Portugal». In Sociabilidades na vida e na morte (séculos XVI-XX). Braga: Centro de Investigação Transdisciplinar CITCEM - Cultura, Espaço e Memória, pp.455-468. http://hdl.handle.net/10174/11631; LALANDA, Margarida Sá Nogueira, «Vida religiosa e trabalho: freiras de clausura no século XVII nos Açores/ Religious life and work: cloistered nuns in the Azores in the 17th century». In A Mulher e o Trabalho / Women and Work. vol. V de A Mulher nos Açores e nas Comunidades. Coord. de Rosa Maria Neves Simas. Ponta Delgada: UMAR-Açores, 2008, pp.1053-1067; MORUJÃO, Isabel, Por trás da grade. Poesia conventual feminina em Portugal (séculos XVI-XVIII), Lisboa: INCM, 2013.

${ }^{5}$ Noutros mosteiros da mesma Ordem, por exemplo em Santa Ana de Ávila, eram normalmente seis as religiosas que formavam a chamada capela de música do mosteiro, mais ligadas portanto à prática instrumental. Cf. VICENTE DELGADO, Alfonso de, La Musica en el monasterio de Santa Ana de Avila (siglos XVI-XVIII). Catálogo. Sociedad Española de Musicologia, Madrid, 1989. 
ou tinham familiares diretos relacionados com a atividade musical, e que asseguravam a continuidade da formação das jovens mesmo intramuros, como fica muitas vezes estabelecido nos contratos de dote, mas cuja presença era sujeita à licença do abade de Alcobaça. Ao baixão e ao baixo, à harpa, ao órgão, à viola d'arco, ao canto, está associada a praxis musical de mais de 20 religiosas no mosteiro, verificando-se uma primazia da presença das tangedoras de órgão no século XVIII, a exemplo do que acontecia noutras comunidades. Em 1625, com D. Paula de Almeida como abadessa, além dos cargos habituais é citada uma Mestra de Cantochão, Maria de Villalobos ${ }^{6}$, ofício pouco documentado no mosteiro. Os livros de Coro de S. Bento de Cástris, alguns com procedência assinalada ${ }^{7}$, denunciam a predominância de algumas temáticas, como as composições dedicadas ao Santíssimo Sacramento, as natalícias e os santos da Ordem. Celebrava-se com grande solenidade o Corpo de Deus, próprio da devoção eucarística pós-tridentina.

No mosteiro havia duas missas quotidianas, tendo as religiosas conversas que assistir pelo menos a uma. Nos Ofícios Divinos, assume especial relevância a atividade do Coro; devia cantar e ir à estante a religiosa que fosse nomeada pela Cantora-mor, acompanhada pelas outras vozes. Também ela faria guardar e respeitar o grau das religiosas no Coro e estabelecer semanalmente uma tábua com as obrigações do mesmo: assegurar o Invitatório, as Lições e Versos, levantar antífonas, entre outras obrigações, de molde a evitar inquietações particularmente na celebração das Matinas. Esta tábua dos Ofícios, que compreendia também as leituras no Refeitório, devia ser lida à Sexta-feira, como em todos os mosteiros da Congregação Na Visita de 1667 foi exigido que não fosse descuidada a aprendizagem do cantochão. Doze anos depois, determinaram os Visitadores que o canto deveria ser da responsabilidade de quem soubesse cantar, mesmo que também tocasse instrumento, obedecendo à Mestra da Capela - cargo este de que encontramos raras referências. A abadessa devia sempre nomear para este ofício uma religiosa a que todas as religiosas músicas obedecessem, porque, normalmente, eram remissas em acudir ao canto de órgão ${ }^{8}$.

\footnotetext{
${ }^{6}$ [B.P.E.], Cód. CXXXI/2-21.Trata-se de um período em que o mosteiro contava com grande número de religiosas.

${ }^{7}$ Um dos monges copistas dos Livros de Coro de Cástris foi frei António de Araújo, duas vezes confessor neste mosteiro (1663-1666 e 1678-1680), em 1666, confessor em Celas, em 1669 mestre dos noviços de Alcobaça, e em 1672 prelado em S. Pedro das Águias; ou, desde Alcobaça, Fr. Rodrigo das Dores, em 1798, havendo notícias de despesas com os livros em que trabalhou. Cf. Biblioteca Pública de Évora [B.P.E.], Cód. CXXXII/1-18, set/dez 1798, fl 16.

${ }^{8}$ [B.P.E.], Cód. CXXXI/2-23, fl.110.
} 
Em março de 1691 Frei Jerónimo de Saldanha, Abade Geral e Esmoler-mor, na sua Visita ao mosteiro lembrou que a passagem de noviça a professa só era feita após um exame de conhecimentos de reza e cerimónias, mas também de cantochão. A questão do não cumprimento do mosteiro nestas matérias fica demonstrada na Pastoral que frei Bento de Melo, Abade Geral, lhes dirigiu, por lhe ter constado que as religiosas não cumpriam duas das Leis ditadas pelo Capítulo intermédio desse mesmo ano, sendo uma delas a que proibia o canto de órgão ou canto figurado ${ }^{9}$ nas Igrejas e Coros. A Pastoral sublinha que a música figurada, com acompanhamento de órgão, conduzia a notáveis relaxações nos mosteiros das religiosas, devendo suspender-se, e usar-se só o cantochão grave, pelo que encarregava o Padre Confessor de fazer observar essa determinação e de informar o Abade de quem se esquivasse. Tais determinações, no que respeita à música e ao canto, foram retomadas nos Capítulos de 1729,1732 e 1735.

No espaço entre os capítulos o controlo cabia às Juntas, que, in loco, verificavam não só as questões de contabilidade e gestão das comunidades como aferiam a vida quotidiana e a prática litúrgica, dando indicações claras e precisas: em 1728 a Junta, em visita ao mosteiro de S. Bento de Cástris, sublinhava que:

(...) as Madres Donas Abadessas tenhão especial cuidado, e as Mestras dos Noviciados, de fazerem aprender o cantochão às Noviças e as Religiosas mudernas que tiverem só quatro anos de hábito, deputando-lhe Mestras que as ensinem, e hora em que todos os dias se ocupem em aprender enquanto não souberem bem; e terão muito cuidado de aplicar as que tiverem habilidade para apender a tocar órgão determinando-lhe Mestra que as ensine pessoa recolhida no mosteiro ou religiosa dele, e sendo necessário aprenderem canto figurado para melhor perícia do órgão, o aprendam com pessoas do Mosteiro e não poderá ser admitido Mestre de fora sem licença in scriptis do Nosso Reverendíssimo. $(\ldots)^{10}$.

O Visitador Geral da Congregação de Alcobaça, frei Francisco de S. Miguel, em visita ao mosteiro a 10 de setembro de 1766 , sublinhava que o coro do mosteiro era mal servido,

\footnotetext{
${ }^{9}$ Para as questões da prática do canto, “(...) De acuerdo a G. B. Inama y M. Less (1892), las rúbricas tridentinas y la legislación católica basada en ellas han reconocido, a partir de finales del siglo XVI, tres grandes categorías estilísticas de música religiosa, atribuyéndoles una jerarquía precisa en el culto divino: el canto llano asumía el primer lugar, gracias a su origen, íntimamente asociada a la historia de la propia Iglesia; el canto figurado, canto de órgano o, a partir del siglo XVII, estilo antiguo, ocupaba el segundo puesto, en virtud de su relación con el espíritu de la Contrarreforma, considerándose las obras de Giovanni Pierluigi da Palestrina (1525? - 1594) su más alto grado de perfección; el estilo moderno ocupó la tercera categoría, dependiente de aprobaciones eclesiásticas: Monteverdi ha designado, como prima prattica, aquella que "busca la perfección de la harmonía, es decir, aquella que considera a la harmonía no comandada, pero comandando, no como sierva, pero como señora de las palabras". La seconda prattica, para Monteverdi, es aquella que "busca la perfección de la melodía, es decir, aquella que considera la harmonía no comandando, pero comandada, haciendo de las palabras señoras de la harmonía. (...)". Cf. CASTAGNA, Paulo, "Prescripciones tridentinas para la utilización del estilo antiguo y del estilo moderno en la música religiosa católica (1570-1903)", Primer Congreso Internacional de Musicologia. Buenos Aires (Argentina): Instituto Nacional de Musicología "Carlos Vega", 19-22 de outubro de 2000. Santiago de Chile: Instituto de Historia / Pontificia Universidad Católica de Chile, 2002, disponível em http://www.hist.puc.cl/programa/documentos/Castagna.pdf

10 [B.P.E.], Cód. CXXXI/2-7, fl. 21.
} 
dada a falta de comparência das religiosas, lembrando-lhes que elas, como "domésticas de Deus" eram obrigadas à assistência ao Ofício Divino no Coro, sob pena de serem privadas de grade ${ }^{11}$. Esta medida foi agravada pouco depois na visita do Abade Geral, frei Nuno Leitão, em que a falha ao coro (excepto para as doentes) significaria não apenas a retirada de grades, mas também de portaria, a retirada e expulsão do mosteiro de criada particular e ainda o pagamento às custas da religiosa dos ofícios do coro ${ }^{12}$.

Para afastamento dos perigos do mundo, a Junta de 1748 reforçara também já a ideia de que não devia haver nos mosteiros de religiosas comédias, óperas, bailes ou autos ${ }^{13}$. Em Cástris essa prática continuava em inícios do século XVIII ${ }^{14}$, ao verificar-se que nas grades se representavam, com presença de familiares, bailes e entremeses e se lançavam loas ${ }^{15}$, não só de criadas como também de religiosas e educandas. O teatro, particularmente as comédias representadas por mulheres, eram uma ameaça para a Castidade, no dizer do P. Manuel Bernardes:

Mas respondendo direitamente à pergunta, he sem duvida que o assistir às comedias, do modo que hoje se usão, danifica, ou pelo menos arrisca a Castidade. Porque o que ordinariamente vemos nellas, são assumptos amatorios representados por mulheres moças de roim viver, bailes indecentes, trajes descompostos ( $\&$ às vezes transpostos, saindo a femea com vestidos de varão) affectos lascivos metidos em verso, para se pregarem mais na memoria tonilhos, \& sarabandas muy picadas, que parece as inventou o diabo, galanteyos tecidos com tal arte sobre a trama da historia, ou fabula, que a alma gosta do mesmo veneno que está bebendo. (...) No theatro tudo he rizo, desproposito, pompa do diabo, derramamento dos sentidos, esperdiço do tempo, malogro dos dias superfluos: alli se acha a indução dos máos desejos, a meditação do adulterio, a palestra da luxuria, a escola da intemperança, a exhortação à torpeza, \& os exemplos da deshonestidade. (...)"16. Embora reconheça alguns benefícios da comédia, como a capacidade de eloquência, a boa disposição, os conhecimentos que proporciona, eles não deixavam de ameaçar a castidade, fim último do seu Tratado espiritual: “(...) Que importa pois que tiremos da comedia o divertimento da melancolia, a noticia das historias, os termos da eloquencia, ou urbanidade: se por outra parte alli perdemos a modestia, a devoção, a Castidade, o tempo necessario

\footnotetext{
${ }^{11}$ [B.P.E.], Cód. CXXXI/2-2, fl. 8. Nesta Visita ficou ainda sublinhado o dever de obediência à Cantora-mor, tanto na encomenda de Ofícios como quando mandasse as religiosas de um Coro para outro para maior perfeição nos cânticos, ficando os coros mais equilibrados. Cf. CONDE, Antónia Fialho, "O reforço da clausura no mundo monástico feminino em Portugal e a ação disciplinadora de Trento", in As mulheres perante os tribunais do Antigo Regime na Península Ibérica (coord. Margarita Torremocha Hernandez; Isabel Drumond Braga). Coimbra, Imprensa da Universidade, 2015, pp. 235257. DOI: http://dx.doi.org/10.14195/978-989-26-1033-7 10,

${ }^{12}$ Idem, Fl. 9.

${ }^{13}$ Idem, fl. $95 \mathrm{v}$.

${ }^{14}$ Idem, fl. 107.

15 “(...) Loa, s.f. prologo de Drama, no qual de ordinario havia louvores da obra. f. discurso em louvor, ou louvor v.g., merece a loa dos antigos militares. (...) P. D. Raphael Bluteau (1789). Diccionario da Lingua Portugueza, Lisboa : Na Officina de Simão Thaddeo Ferreira, 1789, Vol. 2, p. 30.

${ }^{16}$ P. Manuel Bernardes, Armas da castidade, Lisboa, Oficina de Miguel Deslandes, 1699, pp. 265, 266.
} 
para cousas serias, \& o espirito evangelico; \& vimos dalli todos repassados em espirito mundano, \& affecto a estas cousas visiveis, \& caducas?(...) ${ }^{\prime 17}$.

De qualquer modo, a presença do teatro na vida conventual feminina tem merecido algumas reflexões recentes, procurando demonstrar a sua eficiência face a leituras comunitárias em voz alta, e que poderia funcionar como ferramenta pedagógica e educacional na transmissão dos ideiais de perfeição, castidade e obediência em ambiente de clausura, numa realidade em que predominava a iliteracia (apesar do domínio dos princípios basilares a nível educativo - ler, escrever e contar $)^{18}$.

O padre Manuel Bernardes não deixa de se debruçar também sobre a música e a praxis musical, analisando o panorama musical coevo e o quanto prejudicava a castidade:

(...) Quanto às musicas do tempo tambem he grãde o detrimento que nellas padece a Castidade. Porque assim como o canto grave, \& devoto ajuda a levantar o espirito gerando nelle bons pensamentos, \& saudades da Patria Celestial; \& por isso se usa nas Igrejas entre os divinos officios; assim as sarabandas, \& modos muy festivos, \& picados, o distrahem, affeminão \& corrompem; \& por isso se usa nas comedias, nas ceas nupciaes, \& nas musicas, \& discantes dos que de noute fazem pé de janella para os fins com que a mocidade os inquieta. Mas prouvera a Deos que destes lugares não tivera já passado algua cousa também às Igrejas. (...)" ${ }^{p 19}$.

Para o Autor, a voz das mulheres, no canto, representava ainda um maior perigo (comparada à das sereias, ou ao silvo do basilisco), que se estendia às Casas religiosas, particularmente as femininas. Aqui, a sua crítica é dirigida especialmente para o abuso das grades, apontando ainda o descuido dos prelados e preladas em relação a esses mesmos abusos:

(...) Se a voz he de mulher, ainda traz mayor perigo. S. Leão Papa chama atreiçoados aos seus quebros, \& gargantas, \& brandas punhaladas, com que atravessa o coração de quem ouve descuidado. S. Gregório Naziazeno chamalhe canto de Sereas, que cansa certo naufragio. S. Ambrosio usando da mesma fabula avisa que he necessario tapar os ouvidos, como Ulysses fez a seus companheiros com cera; \& atarse bem a Cruz, como elle ao mastro da náo. S. Chrysostomo the chama peste que inflamma o incendio da concupicencia. O Author do livro De singularitate Clericorum $\left[{ }^{20}\right]$ affirma, que mais toleravel he ouvir os silvos de hum basilisco. Por isto as que tem trato meritricio desejão aprender musica, para

\footnotetext{
${ }^{17}$ P. Manuel Bernardes, Armas da castidade, Lisboa, Oficina de Miguel Deslandes, 1699, p. 269.

Cf. Silvia Evangelisti, Nuns: a history of convent life 1450-1700, Oxford, 2007. https://books.google.pt/books?id=sIXWgHQ14DwC\&printsec $=$ frontcover\&dq= $\% 22$ nuns: $+\mathrm{a}+$ history + of + convent + life \&hl $=$ ptBR\&sa=X\&ved=0ahUKEwiM47HmtOHJAhUFuRQKHVyCBKsQ6AEIHjAA\#v=onepage\&q=\%22nuns $\% 3 \mathrm{~A} \% 20 \mathrm{a} \% 20$ history $\% 20$ of $\% 20$ convent $\% 20$ life $\& \mathrm{f}=$ false

${ }^{19}$ P. Manuel, Armas da castidade, Lisboa, Oficina de Miguel Deslandes, 1699, p. 277.

${ }^{20} \mathrm{O}$ Autor, um anónimo africano do século III, defendia o celibato dos clérigos. O texto foi traduzido e comentado por Diane Shane Fruchtman em De singularitate clericorum: a third-century treatise against spiritual marriage. Cf. $\mathrm{http} / / /$ www.episcopus.org/wp-content/uploads/2014/09/Fruchtman-De-Singularitate-Clericorum-For-Episcopus.pdf
} 
combaterem os animos com armas dobradas, pelos olhos, \& pellos ouvidos. Daqui se entenderá quam reprehensivel abuso seja o de algumas Religiosas, que ajuntando-se na grade em visita com seculares, gastão a tarde em motetes, \& chacaras, \& discantes, ostentando cada huma a sua habilidade. Seguem-se as lisonjas, \& applausos, \& rizadas, \& discriçoens conceituosas, ou estulticias verdadeiras. Se esta musica de vozes de mulheres, cheas de melindre, \& affectação faz consonancia com a modestia, \& honestidade propria daquelle sexo, \& estado, na verdade he muyto para nos maravilharmos; \& somente será necessario inventarmos outras definiçoens às virtudes. Porém se faz dissonancia com ellas, vejão lá os Prelados, \& as Preladas como o consentem, \& se lhes corre obrigaçaõ de o remediarem. $(\ldots)^{21}$.

\section{Os órgãos no mosteiro de S. Bento de Cástris e na cidade de Évora: alguns dados}

No mosteiro são particularmente significativas despesas relacionadas com a música e os instrumentos musicais ao longo do século XVIII, conforme podemos aferir na tabela abaixo:

Tabela 1 - As despesas em instrumentos musicais no mosteiro de S. Bento de Cástris

\begin{tabular}{|c|c|c|c|c|}
\hline Ano & $\begin{array}{c}\text { Tipologia de } \\
\text { intervenção nos } \\
\text { instrumentos } \\
\end{array}$ & Local & Encomenda/Compra & Fonte \\
\hline 1663 & Conserto de orgão & Coro baixo & - & $\begin{array}{l}\text { B.P.E., Cód. } \\
\text { CXXXII/2-23, } \\
\text { fl. } 17 .\end{array}$ \\
\hline & $\begin{array}{l}\text { Conserto de cordas e } \\
\text { bordões para a harpa; } \\
\text { conserto do rabecão }\end{array}$ & - & - & $\begin{array}{l}\text { B.P.E., Cód. } \\
\text { CXXXII/1-2, fl. } \\
82 .\end{array}$ \\
\hline 1728 & Conserto de orgão & Coro baixo & - & $\begin{array}{l}\text { B.P.E., Cód. } \\
\text { CXXXII/1-4, fl. } \\
50\end{array}$ \\
\hline 1738 & - & Coro alto & $\begin{array}{c}\text { Novo órgão a Filipe } \\
\text { da Cunha }\end{array}$ & $\begin{array}{l}\text { B.P.E., Cód. } \\
\text { CXXXII/1-8, } \\
\text { fls. } 11 \mathrm{v}, 15,79 \text {. }\end{array}$ \\
\hline 1786 & - & Coro baixo & $\begin{array}{l}\text { Novo órgão, com } \\
\text { remates e pirâmides } \\
\text { lavrados a ouro . } 60 \\
\text { libras de ouro }\end{array}$ & $\begin{array}{l}\text { B.P.E., Cód. } \\
\text { CXXXII/1-15, } \\
\text { fl.7v. }\end{array}$ \\
\hline 1816 & $\begin{array}{l}\text { Composição de um } \\
\text { piano-forte }\end{array}$ & - & - & $\begin{array}{l}\text { B.P.E., Cód. } \\
\text { CXXXII/1-24, } \\
\text { fl. } 7\end{array}$ \\
\hline
\end{tabular}

${ }^{21}$ P. Manuel, Armas da castidade, Lisboa, Oficina de Miguel Deslandes, 1699, pp. 278, 279.

${ }^{22}$ Seguimos a terminologia presente no documento. Pianoforte (fortepiano) pode ser entendido como um antepassado do actual grand piano. As diferenças são sobretudo quanto ao mecanismo de ataque das cordas (martelos) e dimensão da caixa. O piano forte tem um som ainda muito aproximado ao do cravo, apesar de já utilizar a técnica de martelo. Também tem pedais, daí o nome que basicamente significava um "teclado" com capacidade de dinâmica (piano e forte). Para esta explicação agradecemos a ajuda do Dr. Luís Henriques. 
Estes dados sugerem um uso mais variado de instrumentos antes do século XVIII, figurando também a harpa e o rabecão; em Setecentos as despesas centralizam-se em torno do órgão, a par, no século XIX, com as referências ao piano. O novo órgão (encomendado em 1738) foi usado no mosteiro a primeira vez em Maio de 1742, na Calendas do Espírito $\mathrm{Santo}^{23}$. Havia a preocupação de limpeza frequente dos órgãos, ou mesmo envernizamento, como aconteceu após o regresso das religiosas de Odivelas, depois da exclaustração forçada em $1776^{24}$. No século XIX continuam as despesas pontuais com os órgãos (afinação, limpeza, composição), sendo que o uso do piano está comprovado pelas composições que até nós chegaram e que faziam parte do espólio do mosteiro, hoje acessíveis a partir da base de dados Manuscritos Musicais do Projecto FCT ORFEUS $^{25}$. Num relato praticamente contemporâneo com esta a referência, Fialho d'Almeida ${ }^{26}$ faz a seguinte descrição do que encontrou no Coro baixo do mosteiro, numa breve visita:

(...) Posto à esquerda da capela-mor e dela separado por uma grade de ferro forjado, com sua pequena porta ou parlatório (...) Uma esteira ou tapete amortecia o som dos passos: à esquerda a cátedra abadessal, e partindo dela o cadeirado das monjas perdendo-se na sombra... Depois, fronteira à cátedra, o pequeno órgão ou realejo dos ofícios, e uma lâmpada mortiça, pendurada da abóbada, alumiando a estante de pau-santo, aérea e toda fina de relevo e colunazinhas salomónicas, onde se vê aberto um livro de hinos feito no tempo de «D. Anna Rita Peregrina do Desterro: em Alcobaça, por Frei Rodrigo das Dores, $1798 »$, com pinturas e ornatos de algum mérito. (...).

Cumpre-nos aqui estabelecer um paralelismo com o uso do órgão ${ }^{27}$ noutras comunidades religiosas, sendo que temos dados para duas comunidades masculinas, e paraa catedral da cidade:

\footnotetext{
${ }^{23}$ [B.P.E.], Cód. CXXXI/2-21, fl. 28v

${ }^{24}$ A exclaustração deve ser entendida como a ação de colocar fora da claustra (claustro), ou da clausura, quem por ela optou. No consulado pombalino foi determinada a união de comunidades que viviam sob a mesma Regra em mosteiros partilhados, impondo de forma forçada o abandono dos mosteiros de origem. Tal foi o que se passou com a comunidade de S. Bento de Cástris, que foi obrigada a deslocar-se para Odivelas em 1776, regressando ao mosteiro cerca de um ano depois, precisamente após o afastamento de Pombal do governo.

${ }^{25}$ Onde se referem, por exemplo, composições para piano a quatro mãos. Cf. www.orfeus.pt

${ }^{26}$ Fialho d'Almeida, Estâncias de Arte e Saudade, 1824, pp. 160/161.

${ }^{27}$ Lembremos que já em 1537, a Sé de Évora contava com 14 chantres, e, em meados do século XVI, já aí existia uma Escola para jovens do Coro e outra para jovens músicos, com idades entre os 10 e os 20 anos, marcando muitos deles o panorama musical da época. Durante todo o século XVI surgem ainda organistas, a que se juntava um grande número de tangedores e cantores. Cf. ALEGRIA, José Augusto, "A Música em Évora no século XVI (tentativa de esboço histórico)", in A Cidade de Évora, Évora, Boletim de Cultura da Câmara Municipal de Évora, n. ${ }^{\circ}$ 6, Março 1944, pp. 25-43 ; n. ${ }^{\circ}$ s 7-8, Junho-Setembro 1944, pp. 118-132; Idem, Biblioteca Pública de Évora - Catálogo dos Fundos Musicais, Lisboa, Fundação Calouste Gulbenkian, 1977. Cf. ainda, para o caso de Sevilha, BEJARANO PELLICER, Clara, El mercado de la música en Sevilla del Siglo de Oro, Universidad de Sevilla-Fundación Focus-Abengoa, Sevilla, 2013. O Fundo da Fábrica da Sé de Évora testemunha o prolongamento desta actividade, não apenas no que respeita Livro dos recibos dos ordenados dos mestres de música, dos músicos e moços do Coro nos séculos XVII e XVIII, como também pelo Fundo Musical da Sé,
} 
Antónia Fialho Conde, António Camões Gouveia

Do Espírito do Lugar - Música, Estética, Silêncio, Espaço, Luz

Tabela 2 - A aquisição e o conserto de órgãos nas instituições religiosas da cidade de Évora nos séculos XVII e XVIII: alguns dados

\begin{tabular}{|c|c|c|c|c|c|c|}
\hline Ano & $\begin{array}{c}\text { Novo } \\
\text { instrumento/ } \\
\text { conserto }\end{array}$ & $\begin{array}{c}\text { Valor da } \\
\text { obra }\end{array}$ & $\begin{array}{l}\text { Organeiro/ } \\
\text { Organista }\end{array}$ & $\begin{array}{l}\text { Instituição } \\
\text { religiosa }\end{array}$ & Observações & Fonte \\
\hline 1590 & $\begin{array}{l}\text { Contrato } \\
\text { para feitura } \\
\text { de órgão de } \\
\text { sete registos }\end{array}$ & $\begin{array}{l}100.000 \\
\text { réis }\end{array}$ & $\begin{array}{l}\text { António de } \\
\text { Mesquita }\end{array}$ & $\begin{array}{l}\text { Convento de } \\
\text { S. João } \\
\text { Evangelista }\end{array}$ & $\begin{array}{c}\text { Morava em } \\
\text { Lisboa e era } \\
\text { organista do rei }\end{array}$ & $\begin{array}{l}\text { [A.D.E.], Notarial de } \\
\text { Évora, L }{ }^{\circ} 302, \text { fl. } 123\end{array}$ \\
\hline 1654 & $\begin{array}{l}\text { Contrato para } \\
\text { feitura de um } \\
\text { Órgão }\end{array}$ & - & $\begin{array}{l}\text { António } \\
\text { Machado } \\
\text { Pereira }^{28}\end{array}$ & $\begin{array}{l}\text { Convento de } \\
\text { S. Domingos }\end{array}$ & $\begin{array}{c}\text { mestre de fazer } \\
\text { órgãos e } \\
\text { morador em } \\
\text { Lisboa }\end{array}$ & $\begin{array}{l}\text { [A.D.E.], Notarial de } \\
\text { Évora, L }{ }^{\circ} 823 \text {, fl. } 93\end{array}$ \\
\hline 1609 & $\begin{array}{l}\text { Conserto dos } \\
\text { órgãos da Sé }\end{array}$ & - & - & $\begin{array}{l}\text { Catedral de } \\
\text { Évora }\end{array}$ & 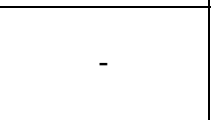 & $\begin{array}{c}\text { [A.C.S.], CEC 13-XV, } \\
\text { Livro dos Acordos } \\
(1608-1611), \text { fl. } 93 \mathrm{v} .\end{array}$ \\
\hline 1654 & $\begin{array}{l}\text { Conserto dos } \\
2 \text { órgãos do } \\
\text { Coro alto }\end{array}$ & - & - & $\begin{array}{l}\text { Catedral de } \\
\text { Évora }\end{array}$ & $\begin{array}{l}\text { Compreendeu } \\
\text { o trabalho do } \\
\text { organista, das } \\
\text { peles para os } \\
\text { foles e do } \\
\text { homem que } \\
\text { levantou esses } \\
\text { mesmos foles }\end{array}$ & $\begin{array}{c}\text { [A.C.S.], Livro de } \\
\text { Receitas e Despesas da } \\
\text { fábrica da Sé de Évora } \\
\text { de 1654-1655, fl. } 10 .\end{array}$ \\
\hline 1655 & $\begin{array}{l}\text { Conserto dos } \\
\text { órgãos } \\
\text { grandes }\end{array}$ & - & - & $\begin{array}{l}\text { Catedral de } \\
\text { Évora }\end{array}$ & $\begin{array}{c}\text { Trabalho } \\
\text { executado por } \\
\text { um organista } \\
\text { vindo de } \\
\text { Lisboa }\end{array}$ & $\begin{array}{c}\text { [A.C.S.], Livro de } \\
\text { Receitas e Despesas } \\
\text { (...) de 1654-1655, fl. } \\
20 .\end{array}$ \\
\hline 1660 & $\begin{array}{l}\text { Cordas para } \\
\text { os órgãos }\end{array}$ & - & - & $\begin{array}{l}\text { Catedral de } \\
\text { Évora }\end{array}$ & - & $\begin{array}{l}\text { [A.C.S.], Livro de } \\
\text { Receitas e Despesas } \\
\text { (...) de 1660, fl. } 42 \mathrm{v} .\end{array}$ \\
\hline 1664 & $\begin{array}{l}\text { Cordas de linho } \\
\text { para os órgãos } \\
\text { da Sé }\end{array}$ & 3.150 réis & - & $\begin{array}{l}\text { Catedral de } \\
\text { Évora }\end{array}$ & - & $\begin{array}{l}\text { [A.C.S.], Livro de } \\
\text { Receitas e Despesas } \\
\text { (...) de } 1664, \text { fl. } 42 \mathrm{v} .\end{array}$ \\
\hline 1676 & $\begin{array}{l}\text { Conserto dos } \\
\text { foles dos } \\
\text { órgãos } \\
\text { grandes } \\
\end{array}$ & - & - & $\begin{array}{l}\text { Catedral de } \\
\text { Évora }\end{array}$ & - & $\begin{array}{c}\text { [A.C.S.], Livro de } \\
\text { Receitas e Despesas } \\
\text { (...) de 1676-1677, fl. } \\
38 \text { v a } 39 \mathrm{v} .\end{array}$ \\
\hline 1677 & $\begin{array}{l}\text { Conserto dos } \\
\text { foles do órgão } \\
\text { grande }\end{array}$ & - & - & $\begin{array}{l}\text { Catedral de } \\
\text { Évora }\end{array}$ & $\begin{array}{l}\text { Foram usadas } \\
48 \text { peles, além } \\
\text { de grude e de } \\
\text { benjoim }\end{array}$ & $\begin{array}{c}\text { [A.C.S.], Livro de } \\
\text { Receitas e Despesas } \\
\text { (...) de 1676-1677, fl. } \\
46 \mathrm{v} .\end{array}$ \\
\hline
\end{tabular}

de que fazem parte Livros de tipologia diversa. Cf. José Augusto Alegria, Arquivo das Músicas da Sé de Évora: Catálogo, Lisboa, Fundação Calouste Gulbenkian, 1973.

${ }^{28}$ Sobre a família dos Machado e a organaria, cf. TUDELA, Ana Paula, "Genealogia socioprofissional de uma família de escultores e organeiros dos sécs. XVIII e XIX: Os Machados - Contributo para o estudo das Artes e Ofícios em Portugal" in Anais - Série História, Universidade Autónoma de Lisboa, 2008, pp. 97-164. 
Antónia Fialho Conde, António Camões Gouveia Do Espírito do Lugar - Música, Estética, Silêncio, Espaço, Luz

\begin{tabular}{|c|c|c|c|c|c|c|}
\hline 1677 & $\begin{array}{l}\text { Conserto dos } \\
\text { órgãos } \\
\text { pequenos e do } \\
\text { órgão grande }\end{array}$ & 1000 réis & $\begin{array}{c}\text { Francisco da } \\
\text { Cunha e seu } \\
\text { ajudante, } \\
\text { Bartolomeu } \\
\text { da Cruz } \\
\text { Andrade }\end{array}$ & $\begin{array}{c}\text { Catedral de } \\
\text { Évora }\end{array}$ & $\begin{array}{l}\text { Francisco da } \\
\text { Cunha era } \\
\text { beneficiado da } \\
\text { Sé de Évora e } \\
\text { seu organista; } \\
\text { foi ainda pago } \\
\text { o homem } \\
\text { encarregado de } \\
\text { levantar os } \\
\text { foles durante } \\
35 \text { dias }\end{array}$ & $\begin{array}{c}{[} \\
\text { A.C.S.], Livro de } \\
\text { Receitas e Despesas } \\
\text { (...) de 1676-1677, } \\
\text { fl.52 }\end{array}$ \\
\hline 1678 & $\begin{array}{l}\text { Conserto dos } \\
\text { órgãos }\end{array}$ & - & - & $\begin{array}{c}\text { Catedral de } \\
\text { Évora }\end{array}$ & $\begin{array}{l}\text { Oficial de } \\
\text { Lisboa }\end{array}$ & $\begin{array}{l}\text { [A.C.S.], CEC 14-III, } \\
\text { "Livro } 31 \text { dos Acordos } \\
\text { (1667-1678)", fl.10. }\end{array}$ \\
\hline 1690 & $\begin{array}{l}\text { Conserto da } \\
\text { tribuna do } \\
\text { órgão } \\
\text { pequeno }\end{array}$ & & & $\begin{array}{l}\text { Catedral de } \\
\text { Évora }\end{array}$ & $\begin{array}{l}\text { Este órgão } \\
\text { encontrava-se } \\
\text { defronte do } \\
\text { órgão grande }\end{array}$ & $\begin{array}{l}\text { [A.C.S.], CEC 14-V, } \\
\text { "Livro } 33 \text { dos Acordos } \\
(1689-1722) \text { ", fl. } 42 \mathrm{v} .\end{array}$ \\
\hline 1690 & $\begin{array}{l}\text { Conserto dos } \\
\text { órgãos }\end{array}$ & 20.000 réis & $\begin{array}{l}\text { Francisco da } \\
\text { Cunha, } \\
\text { frade } \\
\text { organista }\end{array}$ & $\begin{array}{c}\text { Catedral de } \\
\text { Évora }\end{array}$ & $\begin{array}{l}\text { Em 1691, } \\
\text { termina o } \\
\text { órgão, e o } \\
\text { Cabido } \\
\text { encomenda-lhe } \\
\text { um realejo } \\
\end{array}$ & $\begin{array}{c}\text { [A.C.S.], CEC 14-V, } \\
\text { "Livro } 33 \text { dos Acordos } \\
(1689-1722) ", \text { fls. } 46 \mathrm{e} \\
61\end{array}$ \\
\hline 1711 & $\begin{array}{l}\text { Obra de talha } \\
\text { no órgão } \\
\text { grande e } \\
\text { pintura a ouro; } \\
\text { intervenção } \\
\text { geral no órgão }\end{array}$ & & $\begin{array}{l}\text { Francisco } \\
\text { Machado, } \\
\text { entalhador }\end{array}$ & $\begin{array}{c}\text { Catedral de } \\
\text { Évora }\end{array}$ & $\begin{array}{c}\text { Nesse ano, um } \\
\text { pintor dourou o } \\
\text { entalhamento e } \\
\text { pela } \\
\text { intervenção } \\
\text { foram pagos a } \\
\text { um religioso } \\
350.000 \text { réis }\end{array}$ & $\begin{array}{c}\text { [A.C.S.], Livro de } \\
\text { Receitas e Despesas (...) } \\
\text { de 1710-1711, fls. } 52 \mathrm{e} \\
55 \mathrm{v} \text {; Livro de Receitas e } \\
\text { Despesas }(. . .) \text { de } 1711 \text { - } \\
1712, \text { fl. } 18 \mathrm{v} .\end{array}$ \\
\hline 1745 & $\begin{array}{l}\text { Compra de } \\
\text { um órgão }\end{array}$ & & & $\begin{array}{c}\text { Igreja de } \\
\text { Santo Antão }\end{array}$ & $\begin{array}{l}\text { A compra foi } \\
\text { feita pelo então } \\
\text { reitor da } \\
\text { fábrica da } \\
\text { igreja, } \\
\text { Domingos } \\
\text { Cardoso, e dois } \\
\text { anos depois, } \\
\text { em } 1767, \\
\text { estavam a ser } \\
\text { reparados }\end{array}$ & $\begin{array}{c}\text { [A.C.S.], Livro de } \\
\text { Receitas e Despesas da } \\
\text { Fábrica da Igreja de } \\
\text { Santo Antão 1738-1767, } \\
\text { fls. } 56 \text { e 92v. }\end{array}$ \\
\hline 1757 & $\begin{array}{c}\text { Intervenção } \\
\text { na caixa de } \\
\text { um dos órgãos }\end{array}$ & - & - & $\begin{array}{l}\text { Catedral de } \\
\text { Évora }\end{array}$ & $\begin{array}{l}\text { Carpinteiros e } \\
\text { um entalhador }\end{array}$ & $\begin{array}{c}\text { [A.C.S.], Livro de } \\
\text { Receitas e Despesas (...) } \\
\text { de 1757-1758, fls. } 23 \text { v., } \\
25 \text { v., } 26 .\end{array}$ \\
\hline 1760 & $\begin{array}{l}\text { Feitura do } \\
\text { órgão para a } \\
\text { capela mor }\end{array}$ & $\begin{array}{l}1.000 .000 \\
\text { réis }\end{array}$ & $\begin{array}{l}\text { D. Pascoal } \\
\text { Caetano }^{29}, \\
\text { organeiro }\end{array}$ & $\begin{array}{l}\text { Catedral de } \\
\text { Évora }\end{array}$ & $\begin{array}{l}\text { O contrato tivera } \\
\text { lugar em } 1758 ; \\
\text { foi feita a última } \\
\text { parte do } \\
\text { pagamento; } \\
\text { depois, } \\
\text { douramento do } \\
\text { órgão, pago em } 2 \\
\text { vezes }\end{array}$ & $\begin{array}{c}\text { [A.C.S.], Livro de } \\
\text { Receitas e Despesas (...) } \\
\text { de 1760-1761, fls. } 23 \\
\text { e } 25 \mathrm{v} .\end{array}$ \\
\hline
\end{tabular}

${ }^{29}$ Trata-se, naturalmente, de Pascoal Caetano Oldovini. Cf. JANEIRO, João Paulo, "Pascoal Caetano Oldovini: A actividade de um organeiro genovês no Sul de Portugal, no século XVIII", in Organi Liguri, vol. I, Génova, 2004. 


\begin{tabular}{|c|c|c|c|c|c|c|}
\hline 1760 & $\begin{array}{l}\text { Conserto dos } \\
\text { foles e } \\
\text { afinação do } \\
\text { órgão }\end{array}$ & - & $\begin{array}{l}\text { D. Pascoal } \\
\text { Caetano, } \\
\text { organeiro }\end{array}$ & $\begin{array}{l}\text { Igreja do } \\
\text { Colégio do } \\
\text { Espírito } \\
\text { Santo }\end{array}$ & - & $\begin{array}{c}\text { [B.P.E.], Pasta } 3 \text { do } \\
\text { Colégio do Espírito } \\
\text { Santo, doc. } 166 .\end{array}$ \\
\hline 1762 & $\begin{array}{l}\text { Conserto dos } \\
\text { órgãos junto } \\
\text { do Coro alto, } \\
\text { para os } 2 \mathrm{da} \\
\text { Capela mor e } \\
\text { para a } \\
\text { montagem do } \\
\text { órgão } \\
\text { pequeno no } \\
\text { coreto dessa } \\
\text { Capela } \\
\end{array}$ & - & - & $\begin{array}{c}\text { Catedral de } \\
\text { Évora }\end{array}$ & $\begin{array}{c}\text { Para o órgão } \\
\text { pequeno são } \\
\text { ainda referidas } \\
\text { despesas com o } \\
\text { transporte desde } \\
\text { a casa do } \\
\text { organeiro e em } \\
\text { folha de } \\
\text { Flandres. Em } \\
1771 \text { foi retirado } \\
\text { do coreto. }\end{array}$ & $\begin{array}{c}\text { [A.C.S.], Livro de } \\
\text { Receitas e Despesas (...) } \\
\text { de } 1762-1763 \text {, fls. 22, } \\
\text { 25, 25v. e 27. [A.C.S.], } \\
\text { Livro de Receitas e } \\
\text { Despesas (...) de 1770- } \\
1771, \text { fl. } 63 \text { v. }\end{array}$ \\
\hline 1769 & $\begin{array}{l}\text { Conserto dos } \\
\text { foles e } \\
\text { afinação do } \\
\text { órgão }\end{array}$ & - & $\begin{array}{l}\text { D. Pascoal } \\
\text { Caetano, } \\
\text { organeiro }\end{array}$ & $\begin{array}{l}\text { Igreja do } \\
\text { Colégio do } \\
\text { Espírito } \\
\text { Santo }\end{array}$ & - & $\begin{array}{l}\text { [B.P.E.], Pasta } 3 \text { do } \\
\text { Colégio do Espírito } \\
\text { Santo, doc. } 188, \mathrm{n}^{\circ} \\
149 .\end{array}$ \\
\hline 1771 & $\begin{array}{c}\text { Conserto de } \\
\text { um dos órgãos }\end{array}$ & - & $\begin{array}{l}\text { D. Pascoal } \\
\text { Caetano, } \\
\text { organeiro }\end{array}$ & $\begin{array}{c}\text { Catedral de } \\
\text { Évora }\end{array}$ & - & $\begin{array}{c}\text { [A.C.S.], Livro de } \\
\text { Receitas e Despesas (...) } \\
\text { de } 1771-1772, \text { fl. } 65 \mathrm{v} .\end{array}$ \\
\hline
\end{tabular}

O órgão para os dominicanos deveria estar pronto na Semana Santa do ano seguinte ${ }^{30}$. Em 1703, entre as doações de frei Valério de S. Raimundo, bispo de Elvas, ao convento de S. Domingos de Évora constam os órgãos e a sua livraria ${ }^{31}$.

A fervilhante actividade na cidade em torno deste instrumento (feitura, conserto, afinação, instrumentistas) está particularmente documentada para a catedral, como podemos comprovar pela Tabela 2, com intervenção do Cabido e da fábrica da Sé. Além dos dados apresentados na Tabela, sublinhamos ainda que 1690 foi pedido ao "frade dos órgãos" que “(...) faça o orgão de sima cartollado (?) como o grande e que faça hum piqueno de nouo para a Capela major (...)”32. Em 1691, em Março, o Cabido de Évora solicitou ao bispo de Badajoz que enviasse a Évora o seu melhor organista, para aferir a qualidade dos dois órgãos recentemente feitos ${ }^{33}$; no mesmo sentido, em Julho, veio de Lisboa um organista estrangeiro, que confirmou a qualidade dos órgãos e a ausência de defeitos ${ }^{34}$. O conserto dos órgãos sucede-se ao longo do século XVIII ${ }^{35}$, tanto com pequenas intervenções como

\footnotetext{
${ }^{30}$ [A.D.E.], Notarial de Évora, $\mathrm{L}^{\mathrm{o}} 823$, fl. 93; tem assinatura do organeiro, fl. 94v.

${ }^{31}$ BPE, Cód. CXXX/ 1-9, Padre Manuel Fialho, "Évora Ilustrada . Noticias de Évora Antigas, modernas, sagradas e profanas.", tomo $2^{\circ}$, fl. 476 .

32 [A.C.S.], CEC 14-V, "Livro 33 dos Acordos (1689-1722)", fls. 38v. a 39 v.

${ }^{33}$ Idem, fl. $61 \mathrm{v}$.

${ }^{34}$ Idem, fl. $67 \mathrm{v}$.

${ }^{35}$ Em 1702, cf. [A.C.S.], Livro de Receitas e Despesas ... de 1702-1703, fl. 25; em 1703, Livro de Receitas e Despesas ...de 1703 1704, fl. 35 v.; em 1710, Livro de Receitas e Despesas ... de 1710-1711, fl. 42; em 1711, Livro de Receitas e Despesas ... de 1710-1711, fls. 51 - 51 v., fl. 53 v., fl. 55; em 1720, Livro de Receitas e Despesas ... de 1719-1720, fl. 26; em 1725, Livro de Receitas e Despesas ...
} 
em trabalhos mais significativos, como o de Francisco Machado, que já referimos na Tabela 2. Em documentos de 1716 é feita a distinção entre os órgãos pequeno e pequenino da $\mathrm{Sé}^{36}$, este último apontado como estando junto à capela-mor, cujo conserto esteve a cargo do então organista da Sé de Évora, Frei Pedro de S. Bernardino. Em 1727 regista-se um transporte de órgãos, um para a Igreja dos Remédios outro para a Igreja do Colégio do Espírito Santo $^{37}$, não especificando a que título (ocasional ou por ser o seu destino). Nesta igreja, em 1769, em Março, eram pagas a novena, vésperas e festa de S. Francisco Xavier ao P. José de Faria Valle e à sua capela de música na igreja do Colégio ${ }^{38}$; no mesmo ano, o mesmo padre recebeu ainda por serviço semelhante pelo aniversário instituído pela morte do Cardeal D. Henrique ${ }^{39}$. Os serviços a este padre e à sua capela de música aconteciam ainda em 1772 pela festa de S. Francisco Xavier ${ }^{40}$ e no ano seguinte, em Agosto, pelas festas de Santo Inácio e da Senhora da Boa Morte ${ }^{41}$, sempre na igreja do Colégio do Espírito Santo.

A referência à presença (e ao uso) de órgãos na cidade é mais antiga. Para o século XVI, m 1590, os padres lóios ${ }^{42}$ estabeleceram um contrato de obra com António de Mesquita, organista d'El Rei, morador em Lisboa, para que ele lhes fizesse um órgão com sete registos no valor de 100.000 réis. O órgão deveria ficar assente na igreja de S. João Evangelista em Fevereiro de 1591; os padres assegurar-se-iam do transporte desde Lisboa, garantindo o organeiro o concerto de alguma peça que eventualmente quebrasse.

No caso da igreja de Santo Antão, em $1597^{43}$ o Cabido da catedral participou no pagamento a Gaspar Marim, amanhador dos órgãos de Santo Antão ${ }^{44}$. Porém, já em 1571 o Cabido da Catedral de Évora ordenara o pagamento dos órgãos pequenos para essa igreja a Francisco Varela, organista ${ }^{45}$. Em Outubro de 1572, em provisão assinada pelo arcebispo de Évora, D. João de Melo, é ordenado, através de Manuel do Vale, recebedor do dinheiro

de Évora de 1725-1726, fl. 27 v.; em 1728, Livro de Receitas e Despesas .... de 1725-1726, fl. 27 v.; em 1741, Livro de Receitas e Despesas .. de 1741-1742, fl. 23; em 1743, Livro de Receitas e Despesas ... de 1743-1744, fls. 20, 22; em 1744, Idem, fl. 22 v., [104 v]; em 1748, Livro de Receitas e Despesas ... de 1747-1748, fl. $41 \mathrm{v}$.

${ }^{36}$ [A.C.S.], Livro de Receitas e Despesas ... de 1715-1716, fl. 23 v.; [A.C.S.], Livro de Receitas e Despesas ... de 1716-1717, fl. 20.

${ }^{37}$ [A.C.S.], Livro de Receitas e Despesas ... de 1727-1728, fl. 23.

${ }^{38}$ Idem, doc. $190, \mathrm{n}^{\circ} 151$.

${ }^{39}$ Idem, doc. $194, \mathrm{n}^{\circ} 155$. O cardeal D. Henrique nasceu a 31 de janeiro de 1512 e faleceu no mesmo dia, em 1580.

${ }^{40}$ Idem, doc. $358, \mathrm{n}^{\mathrm{o}} 264$.

${ }^{41}$ Idem, doc. $369, \mathrm{n}^{\circ}$ 273. O mesmo se passou em 1774. Cf. [B.P.E.] Livro 5 do Colégio do Espírito Santo, doc. $187, \mathrm{n}^{\circ} 78$. Neste mesmo Livro, as festas e exéquias repetem-se para os anos seguintes: 1774 - exéquias do Cardeal, doc. 195, $\mathrm{n}^{\circ} 86$; Ascensão, doc. 207; acrescenta-se a festa de S. F ${ }^{\circ}$ de Borja em Outubro de 1773, doc. 215, e, também em 1773, as festas de, S. Francisco Xavier, doc. 220.

${ }_{42}$ Arquivo Distrital de Évora [A.D.E.], Notarial de Évora, Lo 302, fl. 123.

${ }^{43}$ [A.C.S.], CEC 13-XII," Livro das Lembranças (1597-1601) ", fl.[18].

44 [A.C.S.], Livro de Registo de Alvarás do Cabido da Sé de Évora (1566-1598), fl. 279 v.

${ }^{45}$ Idem, fl. $50 \mathrm{v}$. 
da obra de Santo Antão, novo pagamento em valor semelhante, ao mesmo organista, sendo que a confirmação do recebimento pelo organista tem como testemunha Gaspar Lopes, o tangedor dos órgãos de Santo Antão ${ }^{46}$. Em 1576, nova provisão do arcebispo autoriza o pagamento do conserto e afinação destes órgãos a Luís Cardoso, organista ${ }^{47}$. De forma mais sistemática, estes dados podem ficar organizados da seguinte forma:

Tabela 2: A atividade de organistas e organeiros em Évora no período moderno:

alguns dados

\begin{tabular}{|c|c|c|c|}
\hline Data & Igreja/instituição & Organista & Organeiro \\
\hline 1571 & Igreja de Santo Antão & Francisco Varela & Francisco Varela \\
\hline 1572 & Igreja de Santo Antão & $\begin{array}{l}\text { Francisco Varela e } \\
\text { Gaspar Lopes, o } \\
\text { tangedor dos órgãos } \\
\text { de Santo Antão }\end{array}$ & Francisco Varela \\
\hline 1576 & Igreja de Santo Antão & Luís Cardoso & Luís Cardoso \\
\hline 1590 & $\begin{array}{l}\text { Convento de S. João } \\
\text { Evangelista }\end{array}$ & António de Mesquita & António de Mesquita \\
\hline 1597 & Igreja de Santo Antão & & $\begin{array}{c}\text { Gaspar Marim, } \\
\text { amanhador dos } \\
\text { órgãos de Santo } \\
\text { Antão }\end{array}$ \\
\hline 1654 & $\begin{array}{l}\text { Convento de } \mathrm{S} . \\
\text { Domingos }\end{array}$ & - & $\begin{array}{l}\text { António Machado } \\
\text { Pereira }\end{array}$ \\
\hline 1655 & Catedral de Évora & $\begin{array}{l}\text { Organista vindo de } \\
\text { Lisboa }\end{array}$ & 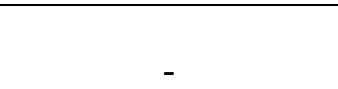 \\
\hline 1668 & Catedral de Évora & Oficial de Lisboa & - \\
\hline 1677 & Catedral de Évora & $\begin{array}{l}\text { Francisco da Cunha, } \\
\text { frade organista }\end{array}$ & $\begin{array}{c}\text { Francisco da Cunha e } \\
\text { Bartolomeu da Cruz } \\
\text { Andrade }\end{array}$ \\
\hline $1690 / 91$ & Catedral de Évora & $\begin{array}{l}\text { Francisco da Cunha, } \\
\text { frade organista }\end{array}$ & Francisco da Cunha \\
\hline 1691 & Catedral de Évora & $\begin{array}{l}\text { Organista de Badajoz; } \\
\text { organista estrangeiro }\end{array}$ & - \\
\hline 1716 & Catedral de Évora & $\begin{array}{c}\text { Frei Pedro de S. } \\
\text { Bernardino }\end{array}$ & $\begin{array}{c}\text { Frei Pedro de } \mathrm{S} . \\
\text { Bernardino }\end{array}$ \\
\hline 1738 & $\begin{array}{c}\text { Mosteiro de S. Bento } \\
\text { de Cástris }\end{array}$ & - & Filipe da Cunha \\
\hline 1760 & Catedral de Évora & - & $\begin{array}{c}\text { D. Pascoal Caetano } \\
\text { Oldovino }\end{array}$ \\
\hline 1760 & $\begin{array}{c}\text { Igreja do Espírito } \\
\text { Santo }\end{array}$ & - & $\begin{array}{l}\text { D. Pascoal Caetano } \\
\text { Oldovino }\end{array}$ \\
\hline
\end{tabular}

${ }^{46}$ [A.C.S.], Pasta 10, Santo Antão, doc.9.

${ }^{47}$ Idem, doc. 16 . 


\begin{tabular}{|c|c|c|c|}
\hline 1769 & $\begin{array}{c}\text { Igreja do Espírito } \\
\text { Santo }\end{array}$ & - & $\begin{array}{c}\text { D. Pascoal Caetano } \\
\text { Oldovino }\end{array}$ \\
\hline 1771 & Catedral de Évora & - & $\begin{array}{c}\text { D. Pascoal Caetano } \\
\text { Oldovino }\end{array}$ \\
\hline
\end{tabular}

Como vemos, do conjunto documental relativo à presença de órgãos em algumas igrejas regulares e seculares da cidade de Évora, é possível retirar um conjunto de organistas e organeiros, com funções nem sempre distinguidas nos documentos, que frequentavam a cidade e prestavam serviço em algumas das suas igrejas (nomeadamente a catedral) e conventos. Se o século XVIII especifica especialmente o ofício de organeiro/construtor de órgãos (veja-se D. Pascoal Caetano Oldovino), essa especificação, precisamente com os organeiros e não com os organistas já se verificava em finais do século XVI e inícios do século seguinte.

Naturalmente, são dados em aberto, procurando futuras abordagens e complementos, não podendo porém ser ignorados face aos existentes para S. Bento de Cástris. Por sua vez, os Livros de Feitoria deste mosteiro provam ainda a sistemática despesa com músicos, instrumentistas e cantores exteriores ao mosteiro, em meses nem sempre coincidentes. Em 1672-73, nos meses de agosto, dezembro e maio, há pagamentos a Cantores, Charamelas e um Arpista. No ano seguinte, a mesma despesa, agora em janeiro e março, tal como em 1674-75, mas em agosto, dezembro e abril; em 1699-1700, as mesmas despesas, em agosto e abril; em 1700-1701 em novembro, janeiro, março e abril; em 1701-02, outubro e abril; em 1726-27, outubro e abril; em 1727-28, apenas em março; em 1728-29, apenas em abril; em 1737-38, apenas em março; em 1740-41apenas em fevereiro; em 1749-50 só em março; em 1743-44, só em janeiro e em 1752-53, a mesma despesa para o mês de abril, último ano em que este dado é documentado no mosteiro. Tendo em conta a mobilidade da Páscoa (e da Semana Santa, dentro do período quaresmal), a mais importante festa no calendário litúrgico cristão, março e abril são os meses em que com mais constância se recorreu a músicos exteriores ao mosteiro, a que se segue o mês de agosto, mês da festa de $\mathrm{S}$. Bernardo, seguido do de dezembro, certamente por altura do Natal.

\section{Considerações finais}

S. Bento de Cástris, mosteiro de fundação medieval e retiro eremítico feminino desde 1169, adoptou a observância de Cister em 1275, ficando na obediência do Abade de Alcobaça. A comunidade foi reconhecida capitularmente por Cister em 1278, conhecendo várias 
provações de natureza interna e externa; soube afirmar-se na cidade e na região. No período pós-tridentino, sujeito à vigilância do cumprimento das leis capitulares e das Juntas por Visitadores e Definidores, a nossa análise considerou particularmente a praxis musical, enquanto reflexo das orientações conciliares, visto tratar-se do mosteiro que maior número de livros de Coro legou ao espólio local de todos os mosteiros eborenses, a maior parte recentemente identificados, procurando relacionar essa praxis com a cidade de Évora e a sua reconhecida tradição musical.

A clausura religiosa feminina vivida após o Concílio de Trento não se pode também dissociar de alguma permeabilidade entre o mosteiro e o seu exterior, obedecendo a regras claras, e, de uma forma mais ampla, ao poder das religiosas conseguiam exercer sobre a sua esfera privada e familiar, para além daquele que inegavelmente exercem dentro do seu próprio mosteiro. Se as relações de poder e governo dentro do mosteiro e na sociedade envolvente são interpermeáveis, também a afirmação e a valorização de algumas religiosas e da própria comunidade conventual se realizam intra e extramuros, pelo apreço de execuções musicais. Familiares diretos das religiosas entravam em Cástris para ensinarem canto, órgão e outros instrumentos, e executantes locais ou dos arredores participavam nas festividades cíclicas do mosteiro. O entendimento da vivência da clausura deve, em S. Bento de Cástris, ter presente a importância concedida à música como auxiliar tanto do quotidiano espiritual, nas missas diárias e no Ofício Divino, como das ocasiões festivas, acompanhando a vida das religiosas, refletindo e plasmando a fervilhante atividade musical vivida em Évora, como demonstram os dados referentes à prática organística.

A música e o canto nas comunidades monásticas, sentindo restrições ao seu uso e forma de expressão no período pós-tridentino, acabam por ser também um dos principais testemunhos de expressão artística das religiosas deste mosteiro, exemplo partilhado com outros mosteiros neste período, não só a nível nacional como peninsular e europeu. 